\title{
Vignettes on the Value of Failure
}

Gerald Beasley, Marwin Britto, Holly Ann Burt, Samuel "Scott" Hall, Amanda Rinehart, Lorelei Rutledge, Lis Pankl, and Catherine Soehner. (2017). Vignettes on the Value of Failure. Research Library Issues, 292: 10-15, https://doi.org/10.29242/rli.292.3.

To whom it may concern,

My contribution to this piece (14\%) consists of a short vignette on pages 12-13.

Thank you,

Amanda K Rinehart

Data Management Services Librarian

The Ohio State University

Rinehart.64@osu.edu

614-292-3336 
Research Library Issues

RLI 292

2017
/ ASSOCIATION LIBRARIES 


\section{Vignettes on the Value of Failure}

\section{Gerald Beasley, Carl A. Kroch University Librarian, Cornell University}

Early in my career I was encouraged to spend trust funds on rare books-never large amounts, but significant in those days, and enough to allow me to attend occasional auctions. On one occasion, under the usual time pressure, I consulted a few bibliographical resources I had to hand, including the 19th-century catalog of a nearby library, and wrongly concluded that we had just acquired at auction the only publicly accessible copy in the city of one particular printed item. I proudly reported as much to the trust. However, the head of that nearby library was one of the trust's board members. He had a suspicion, checked, and found his library did have the book after all. He telephoned me to point out my mistake and to warn me he would have to report it to the trust. He was being kind but I was mortified. Thankfully the other board members forgave my blunder. I learned not to take research lightly. Take the time. Do it properly. Report it accurately.

(C) 2017 Gerald Beasley. This content is licensed under a Creative Commons Attribution 4.0 International License. To view a copy of this license, visit http://creativecommons.org/licenses/by/4.0/.

\section{Marwin Britto, Social Sciences Librarian, University of Saskatchewan}

Early in my higher education career, I served as the head of the Education Library at a comprehensive regional university in the United States. In my library's initial needs assessment of technology use, my team met with a small group of faculty, who suggested we offer online tutorials for faculty on how best to use a variety of educational technologies. We created the tutorials in the format suggested by the group. Unfortunately, the tutorials had limited usage. It was some 
time before we realized that our choice of methodology in gathering feedback-an open focus session with a group of faculty-limited the opportunity for some to express their actual needs, preferences, and learning styles. Often, it is marginalized individuals who are the least vocal and participatory in group situations, yet they too need specific support and resources. Fortunately, this early failure was only short-term. We conducted another needs assessment and employed a methodology that was more inclusive and afforded all segments of the faculty population an equal voice. The end result was a more robust and inclusive series of tutorials that were well received and frequently used.

(C) 2017 Marwin Britto. This content is licensed under a Creative Commons Attribution 4.0 International License. To view a copy of this license, visit http://creativecommons.org/licenses/by/4.0/.

\section{Holly Ann Burt, Behavioral Sciences Librarian, University of Southern California}

It was to be a survey of librarians in a specific service area; an environmental scan to give new insights into the field. The primary investigator was passionate and the library institutional review board (IRB) acknowledged our proposal. Then personnel changes, the IRB response and outside workloads were among the events that first derailed, then drowned our project. This failure revealed how leadership abandonment, funding cuts, IRB recommendations, personal commitments, and even journal submission requirements could bring research to a screeching halt. Now, when asked the perennial reference question: "Why has nothing been published on my research topic?", in addition to alternative search strategies, I recommend searching the grey literature of poster abstracts, clinical trial registries and databases of research projects in progress. To ferret out additional publications of completed research, I might suggest examining the research topic from various angles, from the framing of the original question to viewing components of the topic in the 
context of the research cycle(s). Our failed project opened my eyes to the complexities behind published research, allowing me insight I now offer to others.

(C) 2017 Holly Ann Burt. This content is licensed under a Creative Commons Attribution 4.0 International License. To view a copy of this license, visit http://creativecommons.org/licenses/by/4.0/.

\section{Samuel "Scott" Hall, Solution Consultant, ServiceNow, formerly IT Manager \& Architect, University of California, Berkeley}

I make failure safe for my team by playing the "bad idea game." We play the bad idea game when we can't seem to solve a tough problem. To play, team members take turns describing the worst solutions they can think of. Fairly quickly someone will mention a terrible idea that has some viability to it. Others will pile on to the idea, and before long we have a great solution with which to move forward. This game provides safety for teammates who are less confident in sharing, resulting in more ideas being shared. It also re-energizes our creative problemsolving process in a fun way.

(C) 2017 Samuel "Scott" Hall. This content is licensed under a Creative Commons Attribution 4.0 International License. To view a copy of this license, visit http://creativecommons.org/licenses/by/4.0/.

\section{Amanda Rinehart, Data Management Services Librarian, The Ohio State University}

As a data management services librarian, one of my staple workshops focuses on writing a data management plan for a grant proposal. A regular criticism of this workshop is that it is not specific enough and some researchers feel that the discussion session is dominated by our medical researchers. Therefore, I decided to customize this workshop for three sub-groups: STEM and agricultural researchers, the social sciences and humanities, and biomedical researchers. This would allow 
me to dive more deeply into discipline-specific data services and allow a greater breadth of voices to be heard. However, attendees did not select the workshop specific to their area. Only $44 \%$ of the biomedical workshop registrants were from that area. The best composition was the social science and humanities workshop, where $80 \%$ of attendees were from target areas. Additionally, overall registration and attendance was remarkably low for all three workshops, ranging from 5 to 11 attendees. Not only did my customized educational material not resonate for the majority of attendees, but fewer attendees meant sparse questions and awkward discussion sessions. In fact, during one workshop, an attendee noticed my search methods when answering a data security question. I explained domain searching with Google and this became the highlight of the workshop, despite not being related to research data management at all. So what went wrong? Did attendees not identify with the discipline areas? Was it too confusing to choose? Simple bad timing? There are so many variables that it is hard to know. The lesson I learned is that researchers may think they want a particular type of educational experience, but experimentation is the only way to know if they are correct. I went back to the general data management plan workshop and our most recent one had 41 attendees that engaged in lively discussion.

(C) 2017 Amanda Rinehart. This content is licensed under a Creative Commons Attribution 4.0 International License. To view a copy of this license, visit http://creativecommons.org/licenses/by/4.0/.

\section{Lorelei Rutledge, Assistant Librarian, and Lis Pankl, Associate Librarian, The University of Utah}

We were invited to teach a two-hour class on cultural competence in the classroom. We spoke to the coordinator of the event and prepared an interactive presentation aimed at new teaching assistants from the College of Education. Aware of the demographics at our institution and in the College of Education, we aimed many of our examples toward white teachers. We sent our presentation to the coordinator for the 
event, who said it looked good. During the class, however, we received little participation from the students. Two weeks after, the coordinator came back to us and said that several students were offended by our presentation, feeling that it was too basic an introduction to cultural competence and that our examples about cultural competence in the classroom should have included learning points for students of color as well. We also learned that the students who attended that day were mostly experienced TAs, not new TAs, and that they had a background in critical cultural communication, not education. As a result of this experience, we are conducting research to learn more about how we can improve the library's services for students of color.

(C) 2017 Lorelei Rutledge and Lis Pankl. This content is licensed under a Creative Commons Attribution 4.0 International License. To view a copy of this license, visit http://creativecommons.org/licenses/by/4.0/.

\section{Catherine Soehner, Associate Dean for Research and User Services, The University of Utah}

When I first became a new manager in a library, I was surprised to learn just how many difficult conversations I would need to have. People weren't doing their jobs to the stated expectations, or there weren't any stated expectations, or I needed to ask someone to do something I was pretty sure they didn't want to do, or other people showed up late (or didn't show up at all) to classes or desk shifts, and yet still others were consistently negative in their approach to the work in front of them. I knew I needed to have conversations with each of these individuals, but had no idea how to do that. Further, when I tried to have these conversations, they went badly, people were more upset and stormed out of my office, and behavior did not change. I was terrified. I hated conflict, so maybe I should reconsider by ability or desire to do this job. Maybe I should re-think my life choices and every decision I've ever made up to this point. Or, maybe I should ask for help. I did all of these things. However, it was finding someone who knew about having difficult conversations and who was willing to 
mentor me that became the key to turning my failure around. It turns out that having difficult conversations is something I could learn and could get better at with practice. I have worked on this aspect of my performance so consistently that I finally wrote a book about it with co-author Ann Darling-Effective Difficult Conversations: A Step-byStep Guide. Without complete failure at the beginning of my career as a leader, I would not have been so dedicated to improving and eventually sharing how I have effective difficult conversations.

(C) 2017 Catherine Soehner. This content is licensed under a Creative Commons Attribution 4.0 International License. To view a copy of this license, visit http://creativecommons.org/licenses/by/4.0/.

To cite this article: Gerald Beasley, Marwin Britto, Holly Ann Burt, Samuel "Scott" Hall, Amanda Rinehart, Lorelei Rutledge, Lis Pankl, and Catherine Soehner. "Vignettes on the Value of Failure." Research Library Issues, no. 292 (2017): 10-15, https://doi.org/10.29242/rli.292.3. 